\title{
Comparison of the Effectiveness of Two Different Extracorporeal Shock Wave Therapy Regimens in the Treatment of Patients With Myofascial Pain Syndrome
}

\author{
Ali GÜR, ${ }^{1}$ İrfan KOCA, ${ }^{1}$ Hilal KARAGÜLLÜ, ${ }^{1}$ Özlem ALTINDAG $\breve{ },{ }^{1}$ Ercan MADENCI், ${ }^{2}$ \\ Ahmet TUTOĞLU, ${ }^{3}$ Ahmet BOYACI, ${ }^{3}$ Mustafa IŞIK ${ }^{4}$ \\ ${ }^{1}$ Department of Physical Medicine and Rehabilitation, Medical Faculty of Gaziantep University, Gaziantep, Turkey \\ ${ }^{2}$ Department of Physical Medicine and Rehabilitation, Medical Faculty of Medeniyet University, İstanbul, Turkey \\ ${ }^{3}$ Department of Physical Medicine and Rehabilitation, Medical Faculty of Harran University, Şanluurfa, Turkey \\ ${ }^{4}$ Department of Orthopedics and Traumatology, Medical Faculty of Gaziantep University, Gaziantep, Turkey
}

\begin{abstract}
Objectives: This study aims to compare the effectiveness of two different regimens of extracorporeal shock wave therapy (ESWT) in the treatment of myofascial pain syndrome.

Patients and methods: Sixty four patients with active myofascial trigger points in the trapezius muscle were included in this study. Patients were randomized into two groups as patients undergoing a single session of low-energy [energy flux density $\left(E D=0.25 \mathrm{~mJ} / \mathrm{mm}^{2}\right)$ ] ESWT (group 1) and patients undergoing three sessions of ESWT with the same energy density, with one-week intervals (group 2). The effectiveness of therapy was evaluated using the number of trigger points, the Patient Global Assessment and Physician Global Assessment scales, the Neck Pain and Disability Scale, the Nottingham Health Profile and the Hamilton Anxiety Rating Scale prior to therapy and at the end of three and 12 weeks.

Results: No serious complication associated with ESWT application was observed. At the end of the treatment, statistically significant improvements were achieved in the number of trigger points, pain, quality of life, and anxiety scores of patients in both groups $(p<0.01)$. When the groups were compared regarding the effectiveness of the treatment, the improvements in the group receiving three sessions of ESWT were higher except for the anxiety scores $(p<0.05)$.

Conclusion: Low-energy ESWT is a safe and well-tolerated therapy for patients with myofascial pain syndrome and can be more efficient when administered as a three-session treatment regimen.

Key words: Extracorporeal shock wave therapy; myofascial pain syndrome; trigger point.
\end{abstract}

Myofascial pain syndrome (MPS) is a musculoskleteral pain disorder characterized by pain caused by hyperirritable spots, defined as trigger points (TP), in one or more taut bands of muscle fibers. ${ }^{1-3}$ The primary objectives of treatment include the deactivation of the TPs, the relaxation of the taut bands, and the breaking of the vicious cycle of pain-spasm-ischemia-pain, which is one of the factors implicated in the physiopathology of MPS.
Among the several treatment methods, ${ }^{4}$ the extracorporeal shock wave therapy (ESWT) is a non-invasive treatment which has recently come into use for musculoskeletal disorders such as calcific tendinitis of the shoulder, epicondylitis, plantar fasciitis, and delayed union or non-union of bone fractures. ${ }^{5}$ Experimental studies suggested that ESWT stimulates osteoblastic activity by causing microtrauma or microfractures, thereby enhancing fracture healing. ${ }^{6-8}$ It is assumed that 
ESWT, when applied in tendinopathies, induces neovascularization by impairing microcirculation around the tendons, stimulates the release of local growth factors, and activates stem cells for tissue regeneration. ${ }^{9}$

In this study, we hypothesized that the vicious cycle of pain-spasm-ischemia-pain can be broken by the neovascularization-inducing effects of ESWT. To the best of our knowledge, although there is no recommended optimal dose, number of shocks or sessions, or treatment regimen for ESWT in MPS, a common practice may be to administer ESWT at a low-energy level for a short duration. Therefore, the presence of any differentiating results obtained by the specific number of treatment sessions performed in our study may pave the way for further studies in terms of the ease of application and treatment costs.

The purpose of this study was to compare the effectiveness of different regimens of ESWT in the treatment of MPS.

\section{PATIENTS AND METHODS}

A total of 108 patients aged 18 to 60 years who were admitted to our Physical Therapy and Rehabilitation outpatient clinic between January 2010 and September 2010, were enrolled. Inclusion criteria were as follows: patients who were diagnosed with MPS and who failed to respond to previous conservative therapies (physical therapy, non-steroid anti-inflammatory drugs, local injections, exercise). However, only 70 patients were found to be eligible for the study. Six of these patients refused to receive ESWT at the initial visit, and the remaining 64 patients were randomized into two groups of 30 patients each (group 1; 24 women and 6 men; mean age $35.90 \pm 11.57$ years) and (group 2; 25 women and 5 men; mean age $37.00 \pm 11.51$ years) (Figure 1), following ethics committee approval. Two patients in each group were reported not to have attended control visits. Most of the patients had a low level of education.

On the other hand, patients diagnosed with fibromyalgia, those with systemic disorders, pregnant women, patients with cardiac

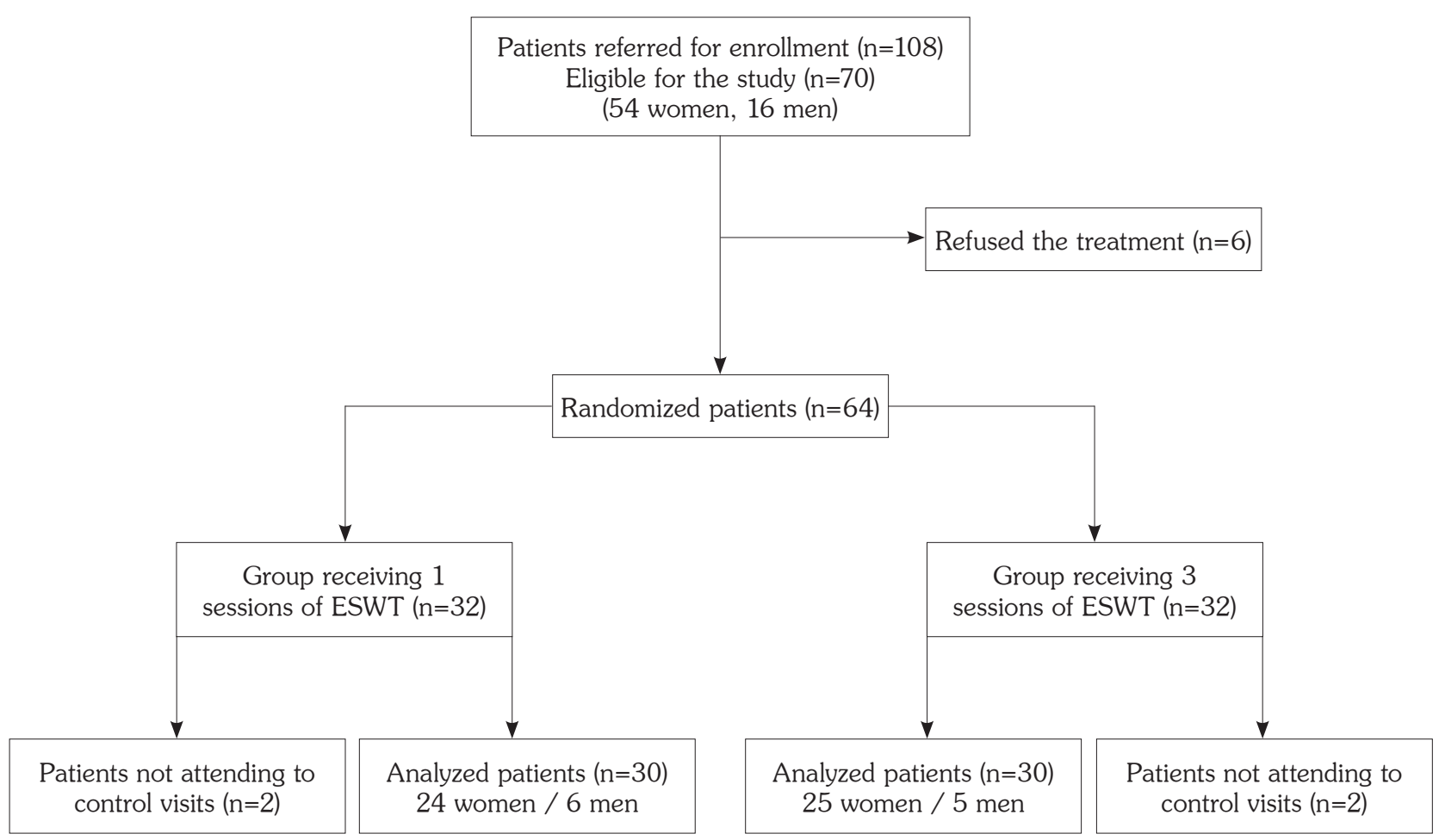

Figure 1. Distribution of patients. 
pacemakers, marked cervical disc lesions, cervical radiculopathies or myelopathies, neurologic disorders and cognitive dysfunction were excluded. Additionally, patients who received local TP injections for myofascial pain within the past six months, those who underwent conservative therapy within the past four weeks, those who underwent neck or shoulder surgery within the past one year, and who were noncooperative were also not included. Prior to treatment, patients were verbally informed of the study, and signed informed consent forms were obtained from all patients. Following a detailed physical examination, a standard evaluation form was completed for each patient. Demographic information such as age, occupation and level of education were recorded. Complete blood count, erythrocyte sedimentation rate and routine biochemistry tests were performed.

The Minilith SL1 shock-wave generator (Storz Medical, Switzerland; ED $=0.25 \mathrm{~mJ} / \mathrm{mm}^{2}, 1000$ shock waves) was used. Group 1 received a single session of ESWT for 10 minutes, while group 2 received three sessions of ESWT with a one-week interval between each session in the same manner. The patients were evaluated prior to treatment followed by three and 12 weeks after treatment. The number of TPs, Patient Global Assessment (PGA) and Physician Global Assessment (MDGA) scales, Neck Pain and Disability Scale (NPDS), Nottingham Health Profile (NHP) and Hamilton Anxiety Rating Scale (HAM-A) were used to assess the effectiveness of the treatments.

Each patient was instructed to indicate with his finger the pain zones along the trapezius. All tender points were marked. Afterwards, the examiner assessed the characteristics of the TPs through palpation. A zero point was given for an increased consistency of a TP in the absence of pain. When the consistency increased one point, the patient reported pain only after an explicit question from the doctor; when the consistency increased two points, the patient reported pain spontaneously; and when the consistency increased three points, the patient withdrew from palpation.

Patients were asked to rate their neck and back pain at rest and on motion in the previous week using a 0-10 cm visual analog scale (VAS). A zero point indicated no pain, and 10 points indicated irresistible pain. The pain intensity before and after treatment was recorded according to the patient's opinion on the PGA scale, and according to the physician's opinion on the MDGA scale. ${ }^{10}$

The NPDS is a 20 -item scale where the patients are asked to respond to each item by marking along a $10 \mathrm{~cm}$ vertical or horizontal line $(0=$ no pain, $10=$ maximal pain). The distance between the mark and the lowest end of the scale is measured, and the obtained numeric value indicates the pain intensity. ${ }^{11}$ The reliability and validity of the Turkish version of the NPDS was evaluated by Biçer et al. ${ }^{12}$ in 2004.

The NHP is made up of 38 statements, which include eight questions on pain, eight questions on physical activity, three questions on fatigue, five questions on social isolation, and nine questions on emotional reactions. The scale provides the percentage of items affirmed in each section, and the total score ranges between zero and $100 .^{13}$ The reliability and validity of the Turkish version of NHP was evaluated by Küçükdeveci et al. ${ }^{14}$

The HAM-A, which measures the level of anxiety on a five-point Likert-type scale, consists of 14 questions. The total score is the sum of individual item scores. Each item is scored between 0 and 4 , and the total score ranges between 0 and 56. Evaluations were made by an independent physician blinded to the study treatments. ${ }^{15}$

\section{Statistical analyses}

The SPSS for Windows version 16.0 (SPSS Inc., Chicago, IL, USA) software program was used for statistical analysis. The Chi-square test was used for the comparison of dichotomous variables between the groups, while the Student's $t$ test was used for the comparison of normally distributed continuous variables, and the MannWhitney U test for variables with non-normal distribution. In the intra-group comparisons of continuous variables, the repeated measure analysis of variance was used for normally distributed variables in the presence of more than two repeated measurements, while the Friedman test $(p<0.05$, with post-hoc Wilcoxon test) was used for variables with non-normal distribution. A $p$ value of $<0.05$ was considered statistically significant. 


\section{RESULTS}

There was no significant difference between the groups with respect to age, sex, duration of illness and body mass index ( $>0.05)$ (Table 1$)$.

The mean intensity of TPs in group 1 and group 2 was $2.03 \pm 0.71$ and $2.36 \pm 0.66$, respectively (Table 2 and 3 ). Significant improvements were achieved at three and 12 weeks after treatment in the number of TPs, pain, PGA, MDGA, NPDS, NHP and HAM-A scores when compared with the pre-treatment values, in both group 1 and group $2,(p<0.01$, for each) (Table 2 and Table 3).

Significant improvements were achieved in the mean intensity of TPs, PGA and MDGA scores at three weeks in group $2(p<0.05)$ than in group 1; however, there was no significant difference between the groups at week 12. Neck Pain and Disability Scale and NHP scores in group 2 at three and 12 weeks were significantly higher than that in group $1(p<0.05)$. There was no significant difference between the two groups with respect to anxiety scores $(\mathrm{p}>0.05)$ (Table 2 and Table 3).

No serious complication associated with the ESWT application was observed. The treatment was generally well-tolerated. Only one patient receiving a single session of ESWT and two patients receiving three sessions of ESWT reported temporary tenderness at the application site.

\section{DISCUSSION}

Our study showed that both one session and three sessions of ESWT significantly reduced the number of TPs, and improved the quality of life and anxiety scores. Furthermore, early treatment outcomes (week 3) showed that a triple session of ESWT was significantly superior to a single session in terms of relieving the pain, reducing the number of TPs, and improving the scores of quality of life.

A study by Müller and Licht, ${ }^{16}$ has demonstrated that ESWT appears to be a promising new modality for the management of MPS. Our results are similar to those of Müller, which suggests improvement in pain scores. In addition, we suggest that our study may contribute to the establishment of an ideal ESWT regimen for MPS patients since we compared two different regimens. We initially thought that pain-related anxiety and low quality of life may benefit from ESWT. In this regard,

Table 1. Demographic features of patients in the two treatment groups

\begin{tabular}{|c|c|c|c|c|c|c|c|}
\hline & \multicolumn{3}{|c|}{ Group $1(n=30)$} & \multicolumn{3}{|c|}{ Group $2(n=30)$} & \multirow[b]{2}{*}{$p$} \\
\hline & $\mathrm{n}$ & $\%$ & Mean \pm SD & $\mathrm{n}$ & $\%$ & Mean \pm SD & \\
\hline Age (years) & & & $35.90 \pm 11.57$ & & & $37.00 \pm 11.51$ & $>0.05$ \\
\hline \multicolumn{8}{|l|}{ Sex } \\
\hline Female & 24 & & & 25 & & & $>005$ \\
\hline Male & 6 & & & 5 & & & $>0.05$ \\
\hline Disease duration (month) & & & $42.13 \pm 52.32$ & & & $33.83 \pm 31.38$ & $>0.05$ \\
\hline Body mass index $\left(\mathrm{kg} / \mathrm{m}^{2}\right)$ & & & $25.71 \pm 4.73$ & & & $25.94 \pm 4.63$ & $>0.05$ \\
\hline \multicolumn{8}{|l|}{ Marital status } \\
\hline Married & 19 & 63 & & 17 & 56 & & $>0.05$ \\
\hline Single & 11 & 37 & & 11 & 37 & & $>0.05$ \\
\hline Divorced & 0 & 0 & & 2 & 7 & & $<0.001$ \\
\hline \multicolumn{8}{|l|}{ Educational status } \\
\hline Illiterate & 4 & 13 & & 0 & 0 & & $<0.001$ \\
\hline Elementary school & 10 & 33 & & 13 & 44 & & $>0.05$ \\
\hline Secondary school & 9 & 30 & & 7 & 23 & & $>0.05$ \\
\hline University/high school & 7 & 24 & & 10 & 33 & & 0.02 \\
\hline \multicolumn{8}{|l|}{ Employment status } \\
\hline Employed & 3 & 10 & & 5 & 17 & & 0.01 \\
\hline Officer & 3 & 10 & & 10 & 33 & & $<0.001$ \\
\hline Housewife & 15 & 50 & & 11 & 37 & & $>0.05$ \\
\hline Others & 9 & 30 & & 4 & 13 & & $<0.001$ \\
\hline
\end{tabular}




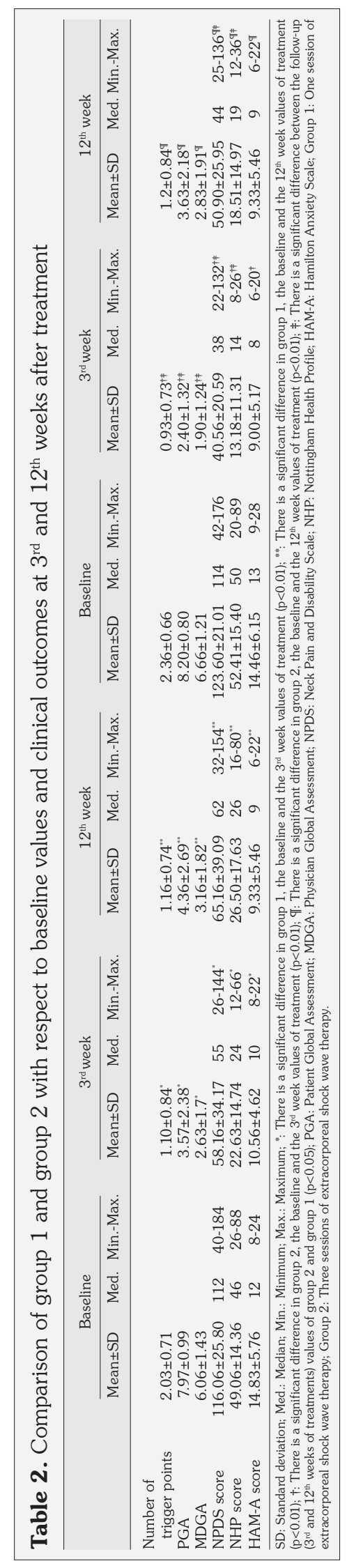

we believe that pain score evaluation would be insufficient for evaluating patient follow-up and treatment efficacy.

In our study, low-energy ESWT was deemed appropriate to minimize the rare local side effects such as skin hyperemia and superficial hematoma. Apart from reduced pain scores, significant improvements were observed in the functional status, quality of life and anxiety scores. These results may be particularly important to support the effectiveness of ESWT in MPS in terms of pain relief and psychosocial interaction. The lowdose of ESWT was well-tolerated and no serious complications occurred.

Helbig et al. ${ }^{17}$ studied the effectiveness of ESWT in the pain management of 150 patients with plantar fasciitis, and lateral and medial epicondylitis. They reported good or very good results in $80 \%, 78 \%$ and $58 \%$ of patients with plantar fasciitis, lateral epicondylitis, and medial epicondylitis, respectively. They also indicated that ESWT was the primary treatment in plantar fasciitis and lateral epicondylitis in particular, and that it is a safe alternative therapy. In another study, Zwerver et al. ${ }^{18}$ evaluated 19 athletes with chronic patellar tendinopathy, and administered three sessions of ESWT in one-week intervals, in incremental doses from medium to high energy level without using local anesthesia. They reported statistically significant improvements in pain and sporting parameters at the end of three months. Additionally, medium-to-high energy ESWT was well-tolerated, and no serious complications were reported. ESWT has been demonstrated to be an effective and safe method in most of these studies, in which sessions ranged from one to three. ${ }^{5,9}$ In our study, we also compared single and triple sessions. Based on our results, we may conclude that increased sessions may increase the cost, possible side effects, and duration of treatment.

It is suggested that certain clinical painrelated conditions, including chronic widespread muscle pain, carpal tunnel syndrome, migraine headaches, temporomandibular joint disorders, and Raynaud's disease are more prevalent in women than in men. In addition, increasing evidence reveals differences between sexes in terms of sensitivity to pain and response to treatment. The number of female patients was higher than males in our study group. 
Table 3. P-values of group 1 and group 2

\begin{tabular}{|c|c|c|c|c|c|c|c|c|}
\hline & \multicolumn{3}{|c|}{ Group 1} & \multirow[b]{2}{*}{$p$} & \multicolumn{3}{|c|}{ Group 2} & \multirow[b]{2}{*}{$p$} \\
\hline & Mean \pm SD & Median & Min.-Max. & & Mean \pm SD & Median & Min.-Max. & \\
\hline \multicolumn{9}{|l|}{ Number of trigger points } \\
\hline Baseline $/ 3^{\text {rd }}$ week & $2.03 \pm 0.71$ & & & $<0.001$ & $2.36 \pm 0.66$ & & & $<0.001$ \\
\hline Baseline $/ 12^{\text {th }}$ week & $1.1 \pm 0.8$ & & & $<0.001$ & $0.9 \pm 0.7$ & & & $<0.001$ \\
\hline $3^{\text {rd }}$ week $/ 12^{\text {th }}$ week & $1.1 \pm 0.7$ & & & $>0.05$ & $1.2 \pm 0.8$ & & & $>0.05$ \\
\hline \multicolumn{9}{|l|}{ NHP pain } \\
\hline Baseline $/ 3^{\text {rd }}$ week & $49.06 \pm 1.4$ & 46 & $26-84$ & $<0.001$ & $52.4 \pm 1.5$ & 50 & $18-88$ & $<0.001$ \\
\hline Baseline $/ 12^{\text {th }}$ week & $22.6 \pm 1.4$ & 24 & $12-64$ & $<0.001$ & $13.2 \pm 1.1$ & 14 & $8-26$ & $<0.001$ \\
\hline $3^{\text {rd }}$ week $/ 12^{\text {th }}$ week & $26.5 \pm 1.7$ & 26 & $16-78$ & $>0.05$ & $18.5 \pm 1.3$ & 19 & $12-36$ & $=0.004$ \\
\hline \multicolumn{9}{|l|}{ NHP function } \\
\hline Baseline $/ 3^{\text {rd }}$ week & $34.8 \pm 16.2$ & 33 & $6-46$ & $<0.001$ & $35.2 \pm 1.7$ & 29 & $6-62$ & $<0.001$ \\
\hline Baseline $/ 12^{\text {th }}$ week & $20.6 \pm 1.8$ & 19 & $8-28$ & $<0.001$ & $8.2 \pm 1.1$ & 8 & $6-20$ & $<0.001$ \\
\hline $3^{\text {rd }}$ week $/ 12^{\text {th }}$ week & $21.9 \pm 1.9$ & 21 & $8-29$ & $>0.05$ & $11.9 \pm 1.4$ & 10 & $8-18$ & $>0.05$ \\
\hline \multicolumn{9}{|l|}{ NHP fatigue } \\
\hline Baseline $/ 3^{\text {rd }}$ week & $50.70 \pm 3.6$ & 48 & $12-66$ & $=0.002$ & $50.7 \pm 2.5$ & 46 & $16-66$ & $<0.001$ \\
\hline Baseline $/ 12^{\text {th }}$ week & $37.4 \pm 2.8$ & 36 & 8-42 & $=0.003$ & $35.2 \pm 3.0$ & 33 & 8-42 & $=0.005$ \\
\hline $3^{\text {rd }}$ week $/ 12^{\text {th }}$ week & $40.7 \pm 2.5$ & 40 & $12-58$ & $>0.05$ & $36.6 \pm 2.9$ & 33 & $12-42$ & $>0.05$ \\
\hline \multicolumn{9}{|l|}{ NHP sleep } \\
\hline Baseline $/ 3^{\text {rd }}$ week & $36.0 \pm 2.6$ & 34 & $16-72$ & $=0.005$ & $34.5 \pm 3.5$ & 29 & $6-44$ & $<0.001$ \\
\hline Baseline $/ 12^{\text {th }}$ week & $25.3 \pm 2.1$ & 25 & $12-54$ & $>0.05$ & $18.8 \pm 2.3$ & 19 & $7-28$ & $<0.001$ \\
\hline $3^{\text {rd }}$ week $/ 12^{\text {th }}$ week & $28.6 \pm 2.4$ & 29 & $13-62$ & $>0.05$ & $10.0 \pm 1.3$ & 9 & $6-24$ & $=0.02$ \\
\hline \multicolumn{9}{|l|}{ NHP Social Isolation } \\
\hline Baseline/3 $3^{\text {rd }}$ week & $8.0 \pm 1.2$ & 9 & $4-22$ & $>0.05$ & $10.0 \pm 1.2$ & 11 & $6-25$ & $<0.001$ \\
\hline Baseline $/ 12^{\text {th }}$ week & $6.6 \pm 1.0$ & 6 & $4-18$ & $<0.001$ & $8.6 \pm 1.2$ & 8 & $6-19$ & $>0.05$ \\
\hline $3^{\text {rd }}$ week $/ 12^{\text {th }}$ week & $8.6 \pm 1.0$ & 9 & $6-22$ & $<0.001$ & $8.6 \pm 1.2$ & 9 & $6-20$ & $>0.05$ \\
\hline \multicolumn{9}{|l|}{ NHP emotional status } \\
\hline Baseline $/ 3^{\text {rd }}$ week & $36.6 \pm 1.9$ & 34 & $6-52$ & $<0.001$ & $29.7 \pm 1.8$ & 28 & $12-42$ & $<0.001$ \\
\hline Baseline $/ 12^{\text {th }}$ week & $22.0 \pm 1.6$ & 23 & $8-33$ & $<0.001$ & $12.8 \pm 1.3$ & 12 & $6-23$ & $<0.001$ \\
\hline $3^{\text {rd }}$ week $/ 12^{\text {th }}$ week & $12.8 \pm 1.4$ & 12 & $6-22$ & $>0.05$ & $12.8 \pm 1.4$ & 13 & $7-24$ & $=0.09$ \\
\hline \multicolumn{9}{|l|}{ HAM-anxiety } \\
\hline Baseline $/ 3^{\text {rd }}$ week & $14.8 \pm 5.7$ & 12 & $8-24$ & $<0.001$ & $14.4 \pm 6.7$ & 13 & $9-28$ & $<0.001$ \\
\hline Baseline $/ 12^{\text {th }}$ week & $10.5 \pm 4.6$ & 10 & $8-22$ & $<0.001$ & $9.0 \pm 5.1$ & 8 & $6-20$ & $<0.001$ \\
\hline $3^{\text {rd }}$ week $/ 12^{\text {th }}$ week & $9.33 \pm 5.46$ & 9 & $6-22$ & $=0.02$ & $9.3 \pm 5.4$ & 9 & $6-22$ & $>0.05$ \\
\hline \multicolumn{9}{|l|}{ NPDS } \\
\hline Baseline/3 ${ }^{\text {rd }}$ week & $116.0 \pm 2.5$ & 112 & $40-184$ & $<0.001$ & $123.6 \pm 21.0$ & 114 & $42-76$ & $<0.001$ \\
\hline Baseline $/ 12^{\text {th }}$ week & $58.1 \pm 3.4$ & 55 & $26-144$ & $<0.001$ & $40.6 \pm 2.6$ & 38 & $22-132$ & $<0.001$ \\
\hline $3^{\text {rd }}$ week $/ 12^{\text {th }}$ week & $65.1 \pm 3.9$ & 62 & $32-154$ & $>0.05$ & $50.9 \pm 4.7$ & 44 & $25-136$ & $>0.05$ \\
\hline
\end{tabular}

SD: Standard deviation; Min.: Minimum; Max.: Maximum; NHP: Nottingham Health Profile; HAM: Hamilton Anxiety Rating Scale; NPDS: Neck Pain and Disability Scale.

The generally lower pain threshold in women may be attributed to serotonin labeling in the spinal cord. However, coping strategies are implemented more often by women than men. Furthermore, most studies have suggested a more significant response among women than men. The majority of patients in our study were women, and their responses to treatment were positive.

The most common treatment methods for MPS include medical therapies, superficial and deep heating modalities, electrotherapy, stretch and spray techniques, acupuncture, local injections, massage, and exercise. However, further research is required to establish more effective and safe treatments. ${ }^{19}$

The shock waves in ESWT are reflected or refracted by the tissues with different acoustic impedances. Therefore, the kinetic energy dissipated in different tissue passages can cause changes within the tissues. ${ }^{5,20}$ Apart from the mechanical effects, shock waves can also cause effects at the cellular level, the most important being the reversible damage or the increased permeability in the neuron membrane. This mechanism can explain the analgesic effects of ESWT. Also, increased blood circulation and hydroxyproline levels have been observed at the 
application sites. In addition, cellular regeneration is accelerated by the neovascularization of the tissue ${ }^{21}$ and the chemical effects of the shock waves are suggested to be mediated by free radicals. ${ }^{22}$ On the other hand, shock waves can rapidly destroy cells by means of free radicals. Structural changes occurring within the cytoplasm and the mitochondria, with an energy flux density of $0.5 \mathrm{~mJ} / \mathrm{mm}^{2}$, have been demonstrated in electron microscopic studies. However, the mean density level of $0.12 \mathrm{~mJ} / \mathrm{mm}^{2}$ is sufficient to change the permeability of the cell membrane. The analgesic effects of ESWT have been demonstrated in many clinical studies; however, the mechanism of this effect is not clearly understood. Apart from neuron membrane damage, some other theories such as nociceptive blockade or central control of sensory input have been put forward, although none has been proved. Another mechanism associated with the analgesic effects of ESWT is the depletion of neuropeptides. ${ }^{23}$ Apart from these, the effects on growth factors and inflammatory process can be regarded among the biological effects of ESWT. Magnetic resonance imaging studies have not revealed any damage on anatomic structures. ${ }^{24}$

We conclude that ESWT may break the vicious cycle of pain-spasm-ischemia-pain by restoring normal vascularization. The $0.25 \mathrm{~mJ} / \mathrm{mm}^{2}$ dose of ESWT, which we administered, may result in a transient damage or increased permeability in the neuron membrane. We suggest that such changes in the TPs after ESWT application may contribute to reduced pain scores. In addition, it is possible that the favorable effects of ESWT on the inflammatory process, the stimulation of tissue regeneration from stem cells, and the depletion of neuropeptides in the painful area may have contributed to the clinical improvement in our patients.

Researches are continued to establish more cost effective and minimally invasive therapeutic maneuvers. ESWT is gradually becoming a common practice in the treatment of musculoskeletal disorders. Further studies comparing various sessions of ESWT are needed to determine the ideal regimen for MPS. Currently, ESWT is administered to MPS patients who are resistant to conventional treatments. Hence, we suggest that ESWT can be placed among the first-line treatments for patients with MPS once the ideal regimen is established. However, the high cost of these devices is the major handicap.
In conclusion, both single session and triple sessions of low-energy ESWT revealed statistically significant improvements in pain, quality of life and anxiety scores of patients with MPS. Additionally, the triple sessions produced a more significant efficacy. As a non-invasive method, ESWT can be regarded as a safe and well-tolerated alternative treatment in patients with MPS when applied at a low-energy level. Nonetheless, further large-scale and long-term follow-up studies are needed to further investigate the application of ESWT in MPS.

\section{Declaration of conflicting interests}

The authors declared no conflicts of interest with respect to the authorship and/or publication of this article.

\section{Funding}

The authors received no financial support for the research and/or authorship of this article.

\section{REFERENCES}

1. Friction JR. Management of myofascial pain syndromes. In: Friction JR, Awad E, editors. Advances in pain research and therapy. New York; Raven Press Ltd.; 1990. p. 325-39.

2. Hong CZ, Simons DG. Pathophysiologic and electrophysiologic mechanisms of myofascial trigger points. Arch Phys Med Rehabil 1998;79:863-72.

3. Sola AE, Bonica JJ. Myofascial pain syndromes. In: Bonica JJ, editor. The Management of pain. Philadelphia: Lea and Febiger; 1990. p. 352-67.

4. Simons DG. Myofascial pain syndromes: where are we? Where are we going? Arch Phys Med Rehabil 1988;69:207-12.

5. Ogden JA, Alvarez RG, Levitt R, Marlow M. Shock wave therapy (Orthotripsy) in musculoskeletal disorders. Clin Orthop Relat Res 2001;387:22-40.

6. Delius M, Draenert K, Al Diek Y, Draenert Y. Biological effects of shock waves: in vivo effect of high energy pulses on rabbit bone. Ultrasound Med Biol 1995;21:1219-25.

7. Haupt G. Shock waves in orthopedics. Urologe A. 1997;36:233-8.

8. Johannes EJ, Kaulesar Sukul DM, Matura E. Highenergy shock waves for the treatment of nonunions: an experiment on dogs. J Surg Res 1994;57:246-52.

9. HellerKD, NiethardFU. Dereinsatzderekstrakorporalen stosswellen therapie in der orthopädecine metaanalyse. Z Orthop 1998;136:391-401.

10. Price DD, McGrath PA, Rafii A, Buckingham B. The validation of visual analogue scales as ratio scale measures 
for chronic and experimental pain. Pain 1983;17:45-56.

11. Goolkasian P, Wheeler AH, Gretz SS. The neck pain and disability scale: test-retest reliability and construct validity. Clin J Pain 2002;18:245-50.

12. Bicer A, Yazici A, Camdeviren H, Erdogan C. Assessment of pain and disability in patients with chronic neck pain: reliability and construct validity of the Turkish version of the neck pain and disability scale. Disabil Rehabil 2004;26:959-62.

13. The European Group for Quality of Life Assessment and Health Measurement: European Guide to the Nottingham Health Profi le. Brookwood-Surrey, Brookwood Medical Publications; 1993. p. 1-16.

14. Kücükdeveci AA, McKenna SP, Kutlay S, Gürsel Y, Whalley D, Arasil T. The development and psychometric assessment of the Turkish version of the Nottingham Health Profile. Int J Rehabil Res 2000;23:31-8.

15. Hamilton M. A rating scale for depression. J Neurol Neurosurg Psychiatry 1960;23:56-62.

16. Müller H, Licht G. Diagnosis and therapy of myofascial pain syndrome with focused shock waves. MOT 2005;5:1-6.

17. Helbig K, Herbert C, Schostok T, Brown M, Thiele $\mathrm{R}$. Correlations between the duration of pain and the success of shock wave therapy. Clin Orthop Relat Res 2001;387:68-71.

18. Zwerver J, Dekker F, Pepping GJ. Patient guided Piezo-electric Extracorporeal Shockwave Therapy as treatment for chronic severe patellar tendinopathy:
A pilot study. J Back Musculoskelet Rehabil 2010;23:111-5.

19. Wals NE, Dumitru D, Schoenfeld, LS, DeLisa JA. Treatment of the patient with chronic pain. In: DeLisa JA, Gans B, editors. Physical medicine \& rehabilitation principles and practice. Philadelphia: Lippincott Williams \& Wilkins; 2005. p. 493-529.

20. Harniman E, Carette S, Kennedy C, Beaton D. Extracorporeal shock wave therapy for calcific and noncalcific tendonitis of the rotator cuff: a systematic review. J Hand Ther 2004;17:132-51.

21. Peers K. Shockwave Therapy-Theory and Practice with the kind support of "ad rem team" Workshop notes, 14th European Congress of Physical and Rehabilitation Medicine- "Advances in PMR- Traditional and Modern Concepts" May 2004.

22. Munver R, Delvecchio FC, Kuo RL, Brown SA, Zhong P, Preminger GM. In vivo assessment of free radical activity during shock wave lithotripsy using a microdialysis system: the renoprotective action of allopurinol. J Urol 2002;167:327-34.

23. Speed CA. Extracorporeal shock-wave therapy in the management of chronic soft-tissue conditions. J Bone Joint Surg [Br] 2004;86:165-71.

24. Cyteval C, Baron-Sarrabère MP, Jorgensen C, Cottin A, Benis J, Sany J, et al. MRI study before and after extracorporal shock wave therapy in calcifying tendinitis of the shoulder. $\mathrm{J}$ Radiol 2003;84:681-4. 